paralysed under other circumstances for a longer time, and as profoundly as under these, and yet not waste so rapidly. Under these conditions of wasting, the nutrition of the muscles may be restored by any form of electricity which will put those muscles into action; but this result is achieved more quickly by the interrupted battery current than by any other. This curious fact you may see again and again, that an amount of faradic foree which will act strongly on a healthy muscle will not act on muscles paralysed in the manner I have described; but that a weak current coming from a simple galvanic battery, slowly interrupted. will act on those muscles to a degree which is more marked than that which you will observe in health. This is a very curious point, and one that is more than curious, for it is very useful in therapeutics. For instance, if a person comes to you paralysed on one side of his face from cold-e.g. from sitting in a draught, - unable to close his eye, and the mouth drawn to one side, if you take a current from a battery of low power, ten eells or so, you will make the muscles flicker when you put it on, making and breaking the current slowly with your finger or with a wet sponge; whereas if you apply it to the healthy side, you will perhaps see no effect whatever. The muscle paralysed here appears to be more sensitive than that which is not paralysed. If you apply faradisation, however, in this condition, to the paralysed side, you see no effect; apply it to the healthy side, and you make the man grimace directly.

There are reasons for thinking, as I have often shown You, that the want of response to faradisation is due to the momentary duration and rapid interruption of the induced current, and to these conditions only; for if you very rapidly interrupt the battery current-just as rapidly, for instance, as you can do it with one of these interruptors of Pulvermacher's chains, or even with your own hand,-the muscles that are paralysed will not act to the battery eurrent, any more than they do to faradisation, whereas those on the opposite side will do so. I think it is clear, indeed, that the want of response to faradisation is a want of functional activity in the musele; it cannot appreciate readily the rapidly interrupted current, from whatever source it may be derived. That is pretty clear; we have seen it again and again. But it has not yet been made out why a muscle in this condition should exhibit an excess of sensitiveness to a slowly interrupted galvanisation. That it does so is perfectly elear; and when it does so, and its nutrition is impaived, the battery current is that which you should use for its restoration.

There are other cases of wasting paralysis in which faradisation is much more useful than the battery current. Under such circumstances use faradisation. The muscles waste, for instance, from disuse in long-standing palsy the result of cerebral disease; and here faradisation is often the best form of electricity that you can employ. In all cases, what you want to do is to put the muscle into action, and you must use that form of electricity which most readily accomplishes this end. You may divide your cases into two categories, those which will respond most readily to the one form of electricity or to the other; and you are to use in each group of cases that mode of appliance which produces the most distinct contraction with the least amount of electric force.

\section{OBSERVATIONS ON SWALLOWING INDI- GESTIBLE SUBSTANCES ;}

WITH THE PARTICULARS OF AN INSTANCE IN WHICH A GOLD PENCIL-CASE PASSED INNOCUOUSLY THROUGH THE GULLET, STOMACH, AND INTESTINES.

\section{BY SIR WILLIAII FERGUSSON, BART.,} SERJELYTT-SURGEON TO THE QLEEN.

CASES are familiarly known, both in domestic annals and among the profession, of indigestible substances having been swallowed and subsequently evacuated from the rectum, without having produced any inconvenience whatever. These have usually been rounded or smooth-edged, such as bullets or coins, and occasionally sharp-pointed or sharp-edged objects, such as gold plates with false teeth, or pins for holding them, or with sharp hooked extremities to grasp neighbouring sound teeth. Even blades of knives have passed innocuously through the tortuous route of the alimentary canal. It is of ten a marvel to the anatomist and physiologist how these have not caught in some of the narrow corners or fringes of mucons membrane. It seems to me more remarkable than that they should catch or be held permanently in some part of such a devious route. Instances are well known of plates, with and without false teeth, and other foreign objects lodging for a time in the gullet or pharynx, some of which have passed downwards, some have been ejected by romiting, or been hooked up by the surgeon, whilst some have remained in their unnatura position for years. I know of a case of this kind, where false teeth and gold plate have remained in the lower part of the gullet for years. A collection of such cases would add an interesting chapter to "The Curiosities of Surgery." Although fatal effects are often produced by foreimn objects in the gullet-by suffocation, ulceration, and opening of the aorta,--experience has proved that the greatest danger is in the stomach and intestines. It is wonderful with what facility a passage has been permitted to the stomach; but after this the "dificulties" have begun. In the museum of the Royal College of Surgeons many remarkable illustrations of the kind are preserved. In particular there is one preparation showing an ordinary dessert-spoon sticking in the ileum and cæcum, which had been swallowed, but had stuck fast there, and caused death by ulceration; and another, a dessert-knife, eleven inches long, which, being arrested in the stomach, had ultimately caused a fatal termination. T'here are also specimens of blades and handles, or eroded portions of pocket-knives, which had been passed per anum. Mr. George Pollock published in the first volume of THE LANCET for 1869 an interesting paper on "Cases in which Artificial Teeth were Dislodored and Swallowed, or Impacted in the Pharynx"; and in the same volume Dr. Bond has recorded an instance where a large buckle for braces was finally, after some weeks' residence in the gullet, pushed down into the stomach, where it caused no inconvenience. Within these two years I have myself seen an instance of the safe passage of four false front upper teeth, with gold settings, in three days, through the stomach and intestinal tube.

Perhaps the most remarkable case ever known of swallowing indigestible materials is that recorded by Dr. Marcet, of Guy's Hospital, in the twelfth volume of the MedicoChirurgical Transactions (1823). John C--, a sailor, twenty-three years of age, in the course of ten years from that date, swallowed at different times at least thirty-five knives. Some of these, or eroded portions, were occasionally vomited or passed per anum. He finally died of exhaustion, after much suffering; and, on opening his body, forty different pieces of blades and handles were found in the abdomen. These were chiefly in the stomach, but some had reached as far as the rectum. One portion of metala back spring, measuring $4 \frac{1}{4}$ in. long-had become impacted in the descending colon, and one end, being sharp pointed, had perforated the coats, so as to project into the peritoneum. Another portion was found in the rectum, with one end projecting throngh, so as to be held fast in the pelvis. It is wonderful how far these portions had proceeded along the intestinal eanal. The separation of the knives into their component parts, the erosion of the metallic portions, and the disappearance of the horn of the handles, all evince the influence of the fluids on these different materials. It might be a question where such effects were chiefly produced ; and, doubtless, the gastric juice would be considered as playing the principal part. If sheer exhaustion had not finally carried this person off, might not all these remaining portions have disappeared in time? Notwithstanding our admiration of hartshorn and of iron, it seems certain that, when thus taken into the body, life is greatly jeopardised; and that in such doses, the sooner evacuation takes place the better for the patient.

But is it reasonable to expect that such large objects will pass through the tortuous course from mouth to anus? The anatomist and physiologist would be inclined to think such a thing impossible, but experience has proved that it is realised occasionally. Instances referred to at the beginning of this paper are examples of the fact; and in the museum of the College of Surgeons a number of portions of metal, knife-backs, \&c., have been preserved as having been evacuated by a soldier who, like his compatriot the sailor, 
had indulged a fancy for swallowing clasp knives. Even the long portion in the descending colon of $\mathrm{C}$ - had been arrested by a kind of accident we may suppose, for, as the anatomist knows, it had passed all the places where it was most likely to have stuck fast-the pylorus, the duodenum, the numerous folds of the small intestines, the valvulæ conniventes-even the ileo-cæcal valve! Yet it stuck fast in a wide part of the larger intestines.

To show that hope may be entertained in some such cases I venture to put the following case on record as the most remarkable that has ever come under my personal observation.

A gentleman about fifty years of age, tall and stout in frame, had tried on several occasions to destroy himself, but had been thwarted in his intentions by the vioilance of his attendants. His habits were occasionally very intemperate, and recently, during such condition, he had tried to throw himself out of window, to set fire to his night-dress, and to stab himself in the abdomen with a breakfast knife. $\mathrm{He}$ had inflicted seventeen wounds in the skin near the umbilicus, but none of them penetrated much beyond the surface. An attendant was in the room with bim day and night, and all edged instruments were carefully kept away.

Early on the morning of January 2nd, 1870, he seemed as if choking, with his head under the bedclothes; but speedily recovered, and when asked what was the matter, he said it was only a cough, and soon became quiet. His attendantfeared that he must have swallowed something, but he denied any such act, and nothing more was said on the subject at the time. Among the articles in his bedroom a gold pencil-case was missed. A careful search was made, but he seemed indifferent as to the result, and expressed his conviction that it was not lost. On the day in question, and the following, he was feverish and occasionally vomited; he could not swallow solids, but partook readily of fiuids. On the third day he took food as usual, and made no. special complaint. There were ample grounds for suspicion that the pencil-case had been swallowed. The patient was silent on the subject, and as no good appeared likely to arise from urging a confession, notbing was said to him about it. He was encouraged to eat solid food, and the attendants were enjoined to watch the alvine evacuations. As I had to dress the wounds on the abdomen, I had ample opportunity of manipulating so as to detect any tender spot within. He occasionally complained of pains, but these seemed to me more imaginary than real.

On January 19th he confessed that he had swallowed the pencil-case, and then I explained what might possibly ensue. In particular, I said that it might find its way to the rectum, and produce irritation there. The following morning he fancied that it was in that locality. I examined, and introduced a lithotomy forceps, but nothing could be felt.

On the morning of the 24th, whilst on the stool, he felt that something unusual had passed, and the case was found in the evacuations. Twenty-two days had elapsed since it had been swallowed, and, with the exception of the annoyances of the first twenty-four hours, when it had doubtless been in the gullet, I doubt if there had been a twinge of pain dependent on its progress downwards. It might have been interesting in a surgical point of view to have extracted it from the rectum; but the story is more valuable as showing what nature may do under similar circumstances. There has been no irritation nor complaint of any kind in the gullet, stomach, or bowels since.

The accompanying figure gives a representation of this curiously travelled pencil-case. Its length was four inches and a quarter; and its thickest part, which held an ornamental stone was half an inch. Its future destination will be, in accordance with the consent of the patient, the museum of the Royal College of Surgeons.

Georgrustreet, Hanorer-square, Jarer, 1570 .

\section{ON MEDICAL E D U C A T I N}

BY F. W. HEADLAND, M.D., F.R.C.P., PHYSICIAY TO CHARLYG-CROSS HOSPITAL.

(Coneluded from page 300.)

THE early training being completed at about the age of eighteen, there comes next in order what I call the intermediate training. This stage of the medical education may be altogether dispensed with. A man may go straight from school and college to his hospital and lectures. This is often done by those who have little time to spare, or who. have entered on their medical studies late in life. But I include this second stage in my scheme for two important reasons: firstly, that a great number, I think I may say the majority, of medical students go through it; secondly, that I think it most desirable that they should do so. This intermediate training may take the form of apprenticeship, assistantship, or tutorial instruction. We suppose the student, as he comes to it, proficient in at least the rudiments of Chemistry and Natural History. It will now be useful to him to know something of the way in which these sciences, in their particular application to man, are utilised or applied by the experienced practiser of Medicine. An initiation in the routine of such practice will prepare him for a more careful study of the principles of his art. In fine, I am of opinion that, in his case, it is a safer method to work back from particulars to generalisations than to proceed in the converse way. I will take as my model that old system of apprenticeship which but a short time ago was insisted upon by one of the many examining boards in London. Students of the present day cannot do better than follow out such a plan. Every teacher in a medical school cannot have failed to perceive the immense advantage which is possessed by the pupils who have been trained in such a school, the benefit which a man derives from knowing what an habitué of his art would do in this case or that, and the more perfect insight which this affords him into the principles of medicine and surgery, which, without this experience, would be boundless and destitute of meaning. The. country practitioner, the surgeon-apothecary, or by whatever name our examining boards may dub him, the man who exercises all branches of his art, the man of wide experience and abundant in daily instances of emergency, the man who, whatever our town-bred physicians may think of him, comes nearer than any other we can think of to the ideal carpos-seems of all men the best fitted to prepare the aspirant for the more elaborate teaching which he is expecting in a school of medicine. I hold an apprenticeship to such a man, an assistantship, perhaps, which shall make the student familiar with the qualities of common drugs, and the method of compounding them, with the more familiar aspects of disease, and the simpler modes of treating it, the very best introduction to the more elaborate studies which await him. I find that there is the widest difference in the world between this pupil, who knows something, however rough and unshapely, of human disorders and their cure, and the bookworm, who may be excellently well read in the theory of physic, but has seen nothing at all of its practical application. The fashioning of the mind of this apprentice may be likened to that rough hewing of the block of marble which is destined for a finished statue in the sculptor's studio. We see in it the shaping out of what is to come, but we have not yet the finished perfection of the work of the carver.

In default of apprenticeship or assistantship, in cases where such a method of teaching may be inconvenient or impossible, the next best thing is a course of tutorial instruction. From the age of eighteen to that of twenty-one the lessons of the early scientific training may be instilled more deeply, and improved upon, by a competent teacher, who shall show the manner in which they are to be applied, and prepare the student for his introduction to the mys. teries of the art of healing. As what $I$ intend is that the later training shall be a sort of finishing school, this tutor will need to prepare his alumnus for it by teaching him the meaning of words, the nature and mode of componading of drugs, the character of the commoner sorts of 